\title{
Optimal operative choice for displaced midshaft clavicle fractures in adolescents: a comparative study of intramedullary flexible nails and plating
}

Jin Li

Wuhan Union Hospital

Saroj Rai

National Academy of Sciences

Renhao Ze

Wuhan Union Hospital

Xin Tang

Wuhan Union Hospital

Ruikang Liu

Huazhong Univeristy of Science and Technology

Pan Hong ( $\nabla$ hongpan2013@foxmail.com )

Wuhan Union Hospital https://orcid.org/0000-0003-2674-3016

Research article

Keywords: clavicle fracture, adolescent, elastic stable intramedullary nail

Posted Date: April 10th, 2020

DOl: https://doi.org/10.21203/rs.3.rs-21710/v1

License: (1) This work is licensed under a Creative Commons Attribution 4.0 International License.

Read Full License 


\section{Abstract}

Background: Traditionally, operative treatment for displaced midshaft clavicle fractures in adolescents has been achieved by a plate and screws. However, a minimally invasive trend in most of the surgeries has led the pediatric orthopedic surgeons to use elastic stable intramedullary nail (ESIN) for displaced midshaft clavicle fractures. This study aims to compare the clinical outcomes of adolescent patients who were surgically treated with the (ESIN) and plate for displaced midshaft clavicle fractures.

Methods: A total of 73 patients, aged between 10 years and 14 years, with displaced midshaft clavicle fractures were treated surgically from January 2014 to January 2018. Patients were categorized into two groups, ESIN ( $n=45$; male 27, female 18$)$ and plate $(n=28$; male17, female 11$)$ according to surgical technique. The preoperative data, including baseline information of the patients, radiographic parameters, and types of surgical procedure, were collected from the hospital database. The postoperative data, including clinical outcome and complications, were collected during the follow-up visit. Clinical outcome was evaluated using the American Shoulder and Elbow Surgeons (ASES).

Results: The average age of the patients in the ESIN group was $12.2 \pm 1.5$ years, and that in the Plate group was $12.2 \pm 1.4$ years. There was a significantly less operative time, reduced estimated blood loss $(\mathrm{EBL})$, shortened hospital stay and smaller incision for ESIN group as compared to the Plate group $(P<0.01)$. The rate of scar concern was much higher in plate $(14 / 28,50 \%)$ than $E S I N(2 / 45,4.4 \%),(P$ $<0.01)$. There was no statistically significant difference in shoulder function between the ESIN group (94.5 \pm 2.8$)$ and the Plate group (95.1 \pm 2.7$), P=0.36$. In all the cases, implant removal was performed between 4 and 12 months postoperatively, and the ESIN group had significantly less operative time, EBL and shortened hospital stay as compared to the plate for implant removal $(P<0.01)$.

Conclusion: Both the ESIN and Plate are safe and effective treatment methods for displaced midshaft clavicle fractures in adolescents. The ESIN is superior to plate in terms of shorter operative time, less intraoperative radiation exposure, shorter hospital stay, less scar concern and easier implant removals. However, ESIN for heavier kids remain cautious.

\section{Background}

The clavicle fracture is one of the most common fractures in the pediatric population and accounts for about $10-15 \%$ of all fractures[1]. The midshaft fracture of the clavicle is the most commonly involved anatomical location [2]. In adults, there has been an increasing trend toward operative interventions due to reported better functional outcomes[3,4,5]. However, the management of displaced midshaft clavicle fractures in adolescents remain poorly investigated with a paucity of robust evidence[6,7,8].

There is a debate on surgical intervention in clavicle fractures in adolescents as the fractures heal exceptionally faster with perfect remodeling. The absolute indications of surgery in adolescents are open clavicle fracture, floating shoulder and associated neurovascular injuries [9]. Still, surgical treatment is 
gaining popularity among surgeons for displaced midshaft clavicle fractures in adolescents for better pain management, earlier return to school, less risk of malunion and nonunion.

Traditionally, operative treatment has been achieved by plate and screws[7,10,11]. Recently, intramedullary fixation is gaining increased interest in the literature[12,13]. To the author's knowledge, there is no head-to-head comparison between the elastic stable intramedullary nail (ESIN) and the plate fixation for displaced midshaft clavicle fractures in adolescents. This study aims to compare the clinical outcomes of adolescent patients who were surgically treated with the (ESIN) and plate for displaced midshaft clavicle fractures.

\section{Methods}

\section{Patients:}

A total of 73 patients, aged between 10 years and 14 years, with displaced midshaft clavicle fractures were treated surgically in our hospital from January 2014 to January 2018. Patients were categorized into the ESIN group and the plate group. Total of 45 patients, including 27 males and 18 females, were included in the ESIN group and 28 patients, including 17 males and 11 females, were included in the Plate group.

Inclusion criteria were: 1) Patients aged between 10 years and 14 years with, 2) displaced midshaft clavicle fracture with, 3) no or minimal comminution.

Exclusion criteria were: 1) Patients aged $>14$ years and $<13$ years, 2) comminuted fracture, 3) pathological fracture, 4) metabolic disease, 5) neuromuscular disorder, 6) open fracture, 7) overweight patients (50 kg or more), 8) previous history of ipsilateral clavicle fracture and 9) follow-up period of less than 24 months.

The preoperative data, including baseline information of the patients, radiographic parameters, and types of surgical procedure, were collected from the hospital database. The postoperative data, including clinical outcomes and any complications, were collected during the follow-up visit.

Visual analogue score (VAS) was used to evaluate the postoperative pain and American Shoulder and Elbow Surgeons (ASES) score was used to evaluate the clinical outcomes[14].

\section{Surgical technique for ESIN (See Figure 1)}

The surgery was performed under general anesthesia. The patient was placed on the supine position on a radiolucent table with a radiolucent bolster between the scapulae. A small skin incision, 1.5 to $3 \mathrm{~cm}$, was made at the fracture site. After the visualization of fracture fragment, the intramedullary canal was reamed using a Kirschner wire (K-wire) from the fracture site to the posterolateral aspect of the clavicle until the $\mathrm{k}$ wire comes out of the skin. The exit point of on the lateral aspect of the clavicle is the entry portal of the ESIN. The diameter of the K-wire should be equal to that of the desired ESIN. Then, the 
fracture was reduced by open reduction, and the reduction was maintained with a tenaculum. The desired sized nail was, then, inserted from the entry portal and passed through the fracture as medial as possible. The wound was washed meticulously with normal saline and closed by an absorbable suture.

\section{Surgical technique for plating (See Figure 2)}

The surgery was performed under general anaesthesia. The patient was placed on the supine position on a radiolucent table with a radiolucent bolster between the scapulae. An incision, $4 \mathrm{~cm}$ to $7 \mathrm{~cm}$, was made along the clavicle. Once the fracture was completely visualized, open reduction was performed. Tenaculum or reduction clamps were used to re-position the fragments. Then a plate of 6 to 8 holes was used to fixate the fracture with at least 4 to 6 cortices on either side of the fracture line. The wound was washed meticulously with normal saline and closed by an absorbable suture.

\section{Postoperative care}

Arm sling was used to immobilize shoulder for 1 to 2 weeks. Active shoulder exercises were encouraged as soon as the pain is reduced. Patients were followed-up in every 1 to 2 months at the out-patient clinic.

Sports activities were allowed according to the radiographic and clinical signs of fracture union.

\section{Elective removal of implants}

The ESIN was usually scheduled for removal at about 4 to 6 months and that of Plate at about 7 to 12 months after the surgery. The shoulder function was evaluated according to ASES at every 3 to 6 month after hardware removal [14].

This study was approved by the Ethics Committee of Tongji Medical College, Huazhong University of Science and Technology. Written consent was obtained from the patient's legal guardians.

\section{Statistical analysis:}

We used SPSS software for the data analysis. All descriptive data were presented as the mean \pm SD. Statistical analysis was performed using SPSS (SPSS Inc, Chicago, IL). A P-value of $<0.05$ is regarded as statistical significance.

\section{Results}

Table 1 shows the demographic parameters of the patients. No statistically significant difference existed between the ESIN group and the Plate group, including sex, age, affected side and weight of the patients $(P<0.01)$. All the patients were followed up for 24 months or more. There was a statistically significant shorter operative time, reduced estimated blood loss (EBL), shortened hospital stay and shorter incision length for the ESIN group as compared the Plate group $(P<0.01)($ Table 2$)$.

Table 1 Patient demographic 


\begin{tabular}{|lllll|}
\hline \multicolumn{2}{|l}{ Parameters } & ESIN $(\mathrm{N}=45)$ & Plate $(\mathrm{N}=28)$ & P value \\
\hline \multirow{2}{*}{ Sex } & Male & 27 & 17 & 0.96 \\
\cline { 2 - 5 } & Female & 18 & 11 & \\
\hline \multirow{2}{*}{ Side } & Left & 18 & 11 & 0.96 \\
\cline { 2 - 5 } & Right & 27 & 17 & \\
\hline \multirow{2}{*}{ Age $(\mathrm{y})$} & & $12.2 \pm 1.5$ & $12.2 \pm 1.4$ & 0.97 \\
\hline Weight $(\mathrm{kg})$ & $38.9 \pm 5.2$ & $39.1 \pm 5.3$ & 0.87 \\
\hline Injury to surgery $(\mathrm{d})$ & $2.0 \pm 0.9$ & $2.2 \pm 0.8$ & 0.43 \\
\hline
\end{tabular}

ESIN = elastic stable intramedullary nail

Table 2 Operative parameters for fracture surgery

\begin{tabular}{|llll|}
\hline Parameters & ESIN $(\mathrm{N}=45)$ & Plate $(\mathrm{N}=28)$ & P value \\
\hline Operative time $(\mathrm{min})$ & $31.1 \pm 0.5$ & $59.8 \pm 6.6$ & $<0.01$ \\
\hline EBL $(\mathrm{ml})$ & $10.4 \pm 3.9$ & $31.1 \pm 9.6$ & $<0.01$ \\
\hline Length of stay (days) & $4.0 \pm 0.8$ & $6.0 \pm 0.8$ & $<0.01$ \\
\hline Length of incision $(\mathrm{cm})$ & $2.4 \pm 0.5$ & $4.8 \pm 0.8$ & $<0.01$ \\
\hline
\end{tabular}

EBL $=$ estimated blood loss

Significant alleviation of pain was noticed in both the groups after the surgery (Table 3). According to VAS, there was no statistically significant difference between the ESIN group and the Plate group at postoperative day $1(P=0.39)$ and average pain response at the first 3 days after surgery $(P=0.38)$.

Table 3 pain management

\begin{tabular}{|llll|}
\hline Parameters & ESIN $(\mathrm{N}=45)$ & Plate $(\mathrm{N}=28)$ & P value \\
\hline VAS before surgery & $7.0 \pm 0.8$ & $7.0 \pm 0.8$ & 0.86 \\
VAS $\left(1^{\text {st }}\right.$ day $)$ & $4.8 \pm 0.8$ & $5.0 \pm 0.8$ & 0.39 \\
VAS $(1-3$ days $)$ & $2.8 \pm 0.8$ & $3.0 \pm 0.8$ & 0.38 \\
\hline
\end{tabular}

VAS = visual analogue scale 
As shown in Table 4, there was no case of nonunion in both groups. But, 2 patients $(7.1 \%)$ in the Plate group suffered refracture after implant removal. The rate of implant prominence was higher in the ESIN (44.4\%) than the Plate group (32.1\%). The rate of surgical site infection (SSI) was low in the ESIN group $(4.4 \%)$ and plate $(7.1 \%)$, however, there was no statistically significant difference between the groups $(\mathrm{P}=$ 0.60). The rate of aesthetic concern was much higher in the plate $(50 \%)$ than $\operatorname{ESIN}(4.4 \%),(P<0.01)$. Implant removal was performed after 4 to 12 months after the surgery. According to the ASES score, there was no statistically significant difference between shoulder function. The ASES score in the ESIN group was $94.5 \pm 2.8$, and that of the Plate group was $95.1 \pm 2.7(P=0.36)$.

Table 4 Outcomes and complications after surgery

\begin{tabular}{|llll|}
\hline Complication & ESIN $(\mathrm{N}=45)$ & Plate $(\mathrm{N}=28)$ & P value \\
\hline Loss of reduction & 0 & 0 & 1 \\
\hline Non-union & 0 & 0 & 1 \\
\hline Refracture & 0 & $2(7.1 \%)$ & 0.08 \\
\hline Major complications & 0 & $2(7.1 \%)$ & 0.08 \\
\hline Implant prominence & $20(44.4 \%)$ & $9(32.1 \%)$ & 0.30 \\
\hline SSI & $2(4.4 \%)$ & $2(7.1 \%)$ & 0.60 \\
\hline Scar concern & $2(4.4 \%)$ & $14(50 \%)$ & $<0.01$ \\
\hline ASES & $94.5 \pm 2.8$ & $95.1 \pm 2.7$ & 0.36 \\
\hline
\end{tabular}

Major complications: loss of reduction, non-union, refracture

SSI: surgical site infection

As in Table 5, there was significantly reduced operative time, EBL and shortened hospital stay for the ESIN group as compared to the Plate group for hardware removal $(P<0.01)$.

Table 5. Clinical parameters for elective surgery of implant removal 


\begin{tabular}{llll} 
Parameters & ESIN $(\mathrm{N}=45)$ & Plate $(\mathrm{N}=28)$ & P value \\
\hline Operative time (min) & $10.0 \pm 3.2$ & $35.0 \pm 2.8$ & $<0.01$ \\
\hline EBL & $7.8 \pm 2.5$ & $23.8 \pm 5.6$ & $<0.01$ \\
\hline Length of stay (day) & $1.8 \pm 0.8$ & $4.0 \pm 0.8$ & $<0.01$
\end{tabular}

ASES = American Shoulder and Elbow Surgeons Standardized Shoulder Assessment Form; EBL = estimated blood loss

\section{Discussion}

Both the ESIN group and the Plate group produced satisfactory clinical outcomes for displaced midshaft clavicle fractures in adolescents. ESIN is superior to plate with shorter operative time, shorter hospital stay, less aesthetic concern and easier implant removal.

Operative management is gaining popularity for clavicle fractures in adults because of better clinical outcomes[15,16]. Children and adolescents are traditionally treated with nonoperative methods due to their remarkable healing and remodeling potential [17]. In this group of the population, nonoperative management results in good functional outcomes $[18,19,20]$. However, many surgeons are still performing surgery to treat clavicle fractures in skeletally immature patients as the surgery has the advantage of earlier return to school, better pain response, and less risk of malunion and nonunion, however, the level 1 evidence is still lacking $[7,10,21]$.

In our study, clinical outcomes after operative management, regardless of the ESIN or plating, were satisfactory and consistent with previous reports[22,23,24]. There were no statistically significant differences in terms of shoulder functions and complications between the two groups. There was no case of nonunion or malunion in both groups.

Evidently, ESIN demonstrated the advantages of minimally invasive approach with a smaller incision, faster surgery, and shorter hospital stay than the plate. Contrast to the previous report of medial to lateral advancement of nail[13,22], ESIN was advanced from lateral to medial in our study. The tip was well buried beneath the skin of the posterolateral aspect of the clavicle.

Previous studies reported the early complications such as nail breakage, bending and threatened skin perforation in the ESIN group [12,22,25]. However, these early complications were not significant in our study, possibly because of routine immobilization in an arm sling for first 1 to 2 weeks and good patient compliance.

In our study, refracture occurred in 2 patients that was consistent with previous reports $[11,20,25]$, and both the fractures resulted from accidental fall after plate removal. 
According to previous reports $[19,26,27]$, the rate of dissatisfaction with the scar after operative treatments ranged from $11 \%$ to $20 \%$. In our study, the rate of aesthetic concern for scar was much higher in the plate group (50\%) than in the ESIN (4.4\%) group, because the length of incision was significantly longer in Plate group.

Removal of hardware was routinely performed in our institute. As shown in result, the removal of ESIN was much easier than a plate with less operative time, less EBL and shorter hospital stay.Removal of ESIN was usually scheduled 4 to 6 months after primary surgery with a small incision on the posterolateral aspect of the clavicle. Removal of Plate was normally scheduled 7 to 12 months after primary surgery, with the same incision as primary surgery.

There were several limitations to our study. Firstly, heavier kids over 50 kilograms were not included. As the obesity is getting prevalent among teenagers, more kids younger than 14 years old weight over 50 kilograms and they all received plating as an operative choice for displaced clavicle fractures in our institute. Secondly, the follow-up was not long enough until skeletal maturity; thirdly, the exact length discrepancy between affected bone and contralateral clavicle was not measured, since the gross appearance seemed normal without complaints from the patients and their parents.

\section{Conclusion}

Both the ESIN and Plate are safe and effective treatment methods for displaced midshaft clavicle fractures in adolescents. ESIN is superior to plate with shorter operative time, shorter hospital stay, less aesthetic concern and easier implant removals. However, ESIN for heavier kids remains cautious.

\section{Declarations}

\section{Ethics Approval and Consent to Participate}

Not applicable.

\section{Consent to publish}

Written consents were obtained from the patients for publication of this paper.

\section{Availability of data and material}

The datasets supporting the conclusion of this article are included within the article. Upon request, raw data can be provided by the corresponding author.

\section{Competing interests}

The authors declare that they have no competing interests.

\section{Funding}


None.

\section{Author's contributions}

$\mathrm{PH}^{*}$ is in charge of the main idea and is the guarantor of integrity of the entire clinical study; $\mathrm{JL}$ and $\mathrm{RHZ}$ are in charge of the study concepts, design, manuscript preparation and editing; $\mathrm{PH}$ and SR are in charge of the language polishing and the grammar revision; RKL and XT is in charge of the collection of the study data. All authors read and approved the final manuscript.

\section{Acknowledgement}

Not applicable.

\section{Abbreviations}

ESIN = elastic stable intramedullary nail; ASES = American Shoulder and Elbow Surgeons.

\section{References}

1. Hagstrom LS, Ferrick M, Galpin R. Outcomes of operative versus nonoperative treatment of displaced pediatric clavicle fractures. Orthopedics. 2015;38:135-

2. Mukhtar IA, Yaghmour KM, Ahmed AF, Ibrahim T. Flexible intramedullary nailing versus nonoperative treatment for paediatric displaced midshaft clavicle fractures. J Child Orthop. 2018;12:104-

3. Canadian Orthopaedic Trauma Society. Nonoperative treatment compared with plate fixation of displaced midshaft clavicular fractures. A multicenter, randomized clinical trial. J Bone Joint Surg 2007;89(1):1-10.

4. McKee RC, Whelan DB, Schemitsch EH, McKee MD. Operative versus nonoperative care of displaced midshaft clavicular fractures: a meta-analysis of randomized clinical trials. J Bone Joint Surg Am. 2012;94(8):675-84.

5. Woltz S, Stegeman SA, Krijnen P, et al. Plate fixation compared with nonoperative treatment for displaced midshaft clavicular fractures: a multicenter randomized controlled trial. J Bone Joint Surg Am. 2017;99(2):106-12.

6. van der Meijden OA, Gaskill TR, Millett PJ. Treatment of clavicle fractures: Current concepts review. J Shoulder Elb Surg. 2012;21:423-

7. Mclntosh AL. Surgical treatment of adolescent clavicle fractures: results and J Pediatr Orthop. 2016;36(1):41-3.

8. Yang S, Andras L. Clavicle shaft fractures in Orthop Clin North Am. 2017;48(1):47-58.

9. Caird MS.Clavicle shaft fractures: are children little adults? J Pediatr Orthop. 2012;32(1):1-4.

10. Suppan CA, Bae DS, Donohue KS, et al. Trends in the volume of operative treatment of midshaft clavicle fractures in children and J Pediatr Orthop B. 2016;25:305-9. 
11. Li Y, Helvie P, Farley FA, et al. Complications after plate fixation of displaced pediatric midshaft clavicle fractures. J Pediatr Orthop. 2018;38:350-3.

12. Frye BM, Rye $S, M c D o n o u g h ~ E B, B a l ~ G K$. Operative treatment of adolescent clavicle fractures with an intramedullary clavicle pin. J Pediatr Orthop. 2012;32(4):334-9.

13. Smekal V, Irenberger A, Struve P, et al. Elastic stable intramedullary nailing versus nonoperative treatment of displaced midshaft clavicular fractures - A randomized, controlled, clinical trial. J Orthop 2009;23(2):106-12.

14. Richards RR, An K-N, Bigliani LU, et al. A standardized method for the assessment of shoulder function. J Bone Joint Surg(Am).1994;3:347-352.

15. McKee RC, Whelan DB, Schemitsch EH, McKee MD. Operative versus nonoperative care of displaced midshaft clavicular fractures: a meta-analysis of randomized clinical trials. J Bone Joint Surg Am. 2012;94(8):675-84.

16. Woltz S, Stegeman SA, Krijnen P, et al. Plate fixation compared with nonoperative treatment for displaced midshaft clavicular fractures: a multicenter randomized controlled trial. J Bone Joint Surg Am. 2017;99(2):106-12.

17. McGraw MA, Mehlman CT, Lindsell CJ, Kirby CL. Postnatal growth of the clavicle: Birth to 18 years of age. J Pediatr Orthop. 2009;29:937-

18. Parry JA, Van Straaten M, Luo TD, et al. Is there a deficit after nonoperative versus operative treatment of shortened midshaft clavicular fractures in adolescents? J Pediatr 2017;37(4):227-33.

19. Calder JD, Solan M, Gidwani S, Allen S, Ricketts DM. Management of paediatric clavicle fractures-is follow-up necessary? An audit of 346 cases. Ann R Coll Surg Engl. 2002;84(5):331-3.

20. Gao B, Dwivedi S, Patel S, Nwizu C, Cruz Al Jr. Operative Vs. Non-operative Management of Displaced Midshaft Clavicle Fractures in Pediatric and Adolescent Patients: A Systematic Review and MetaAnalysis. J Orthop Trauma. 2019;[published online ahead of print]

21. Carry PM, Koonce R, Pan Z, Polousky JD. A Survey of Physician J Pediatr Orthop. 2011;31:44-9.

22. Rapp M, Prinz K, Kaiser MM. Elastic stable intramedullary nailing for displaced pediatric clavicle midshaft fractures: a prospective study of the results and patient satisfaction in 24 children and adolescents aged 10 to 15 years. J Pediatr Orthop. 2013;33(6):608-13.

23. Namdari S, Ganley TJ, Baldwin K, et al. Fixation of displaced midshaft clavicle fractures in skeletally immature patients. J Pediatr Orthop. 2011;31(5):507-11.

24. Mehlman CT, Yihua G, Bochang C, Zhigang Operative treatment of completely displaced clavicle shaft fractures in children. J Pediatr Orthop. 2009;29(8):851-5.

25. Luo TD, Ashraf A, Larson AN, Stans AA, Shaughnessy WJ, Mclntosh AL. Complications in the treatment of adolescent clavicle Orthopedics. 2015;38(4):287-91.

26. Randsborg PH, Fuglesang HF, Røtterud JH, Hammer OL, Sivertsen EA. Long-term patientreported outcome after fractures of the clavicle inpatients aged 10 to 18 years. J Pediatr 2014;34(4):393-9. 
27. Robinson L, Gargoum R, Auer R, Nyland J, Chan G. Sports participation and radiographic findings of adolescents treated nonoperatively for displaced clavicle fractures. Injury. 2015;46(7):1372-6.

\section{Figures}
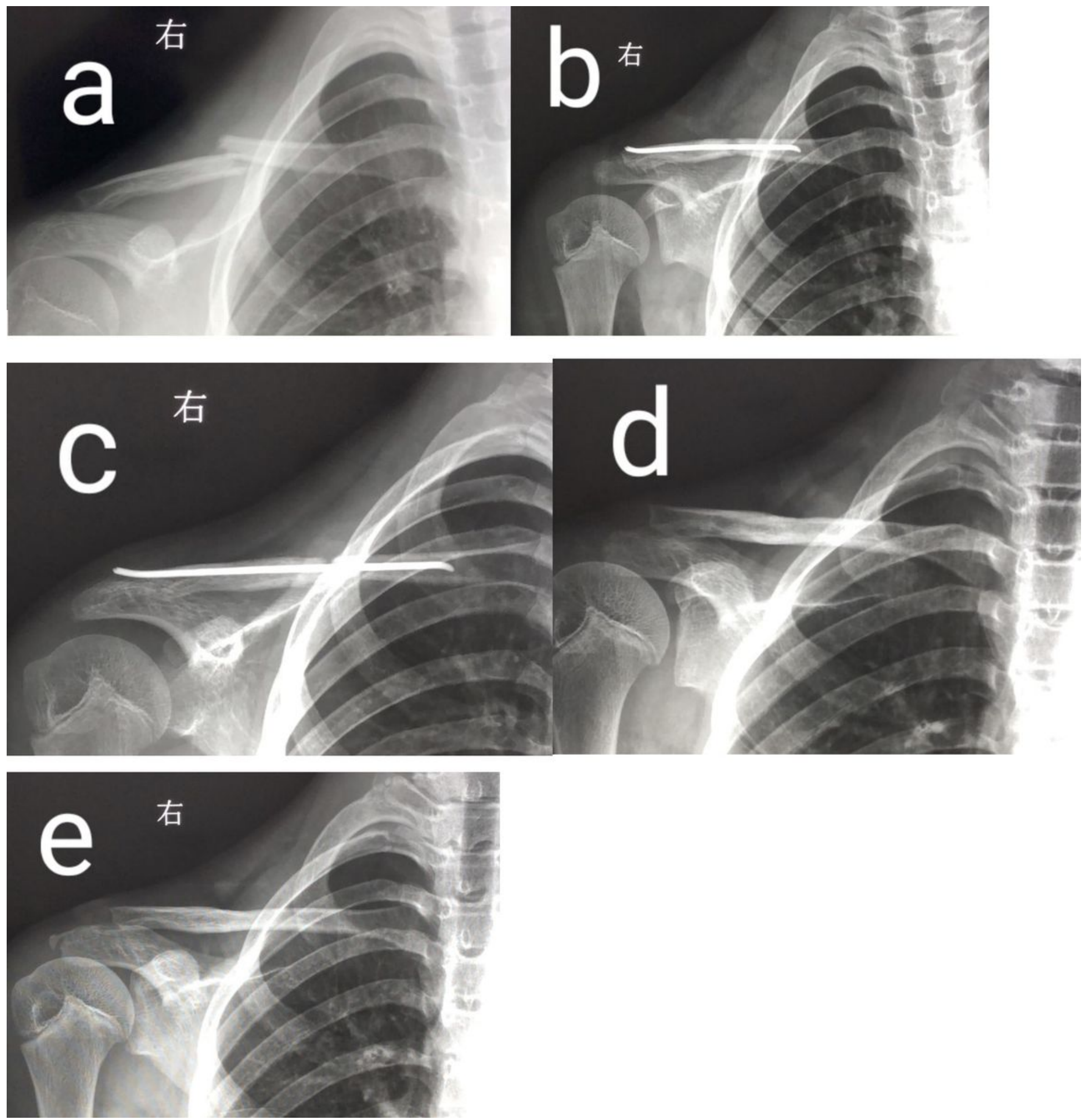

Figure 1 
10 year-old boy of right clavicle fracture treated with ESIN a. AP view of right clavicle before surgery b. AP view of right clavicle after surgery $c$. AP view of right clavicle at 1 month follow-up visit after surgery $d$. AP view of right clavicle after hardware removal e. AP view of right clavicle at 2 month follow-up visit after hardware removal

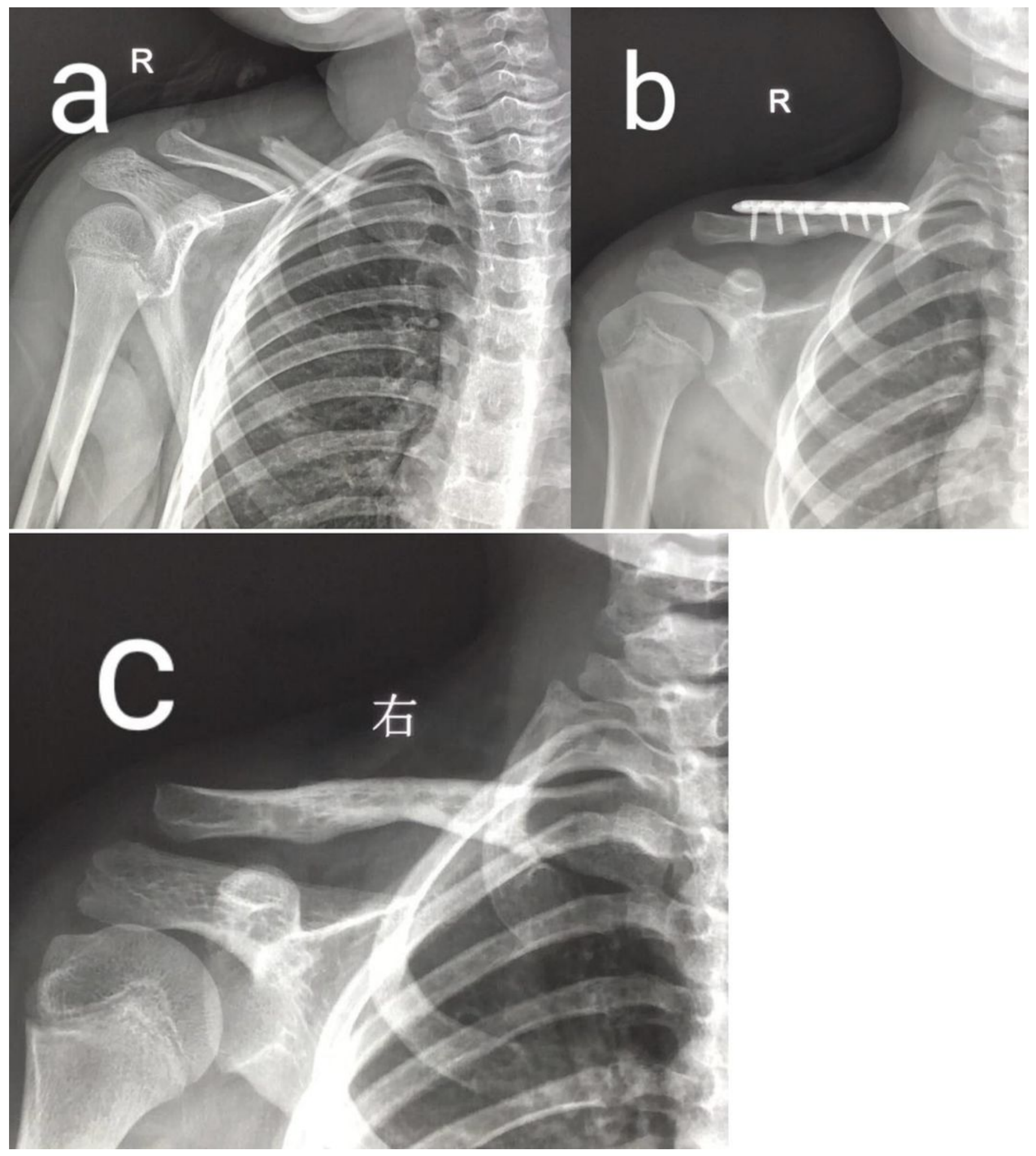

Figure 2 
11 year-old boy of right clavicle fracture treated with plate a. AP view of right clavicle before surgery $b \mathrm{~b}$. AP view of right clavicle after surgery c. AP view of right clavicle after hardware removal 